\title{
Thematic issue: energy provision from organic by-products, residues, and wastes in Asia
}

\author{
B. Deepanraj ${ }^{1} \cdot$ M. Mubarak ${ }^{2} \cdot$ S. Jayaraj ${ }^{3} \cdot$ R. Thundil Karuppa Raj ${ }^{4}$ \\ Published online: 30 July 2020 \\ (C) Springer-Verlag GmbH Germany, part of Springer Nature 2020
}

Due to fast industrialization and increasing population, large quantities of organic wastes are being generated in different forms such as solids, liquids, sludge, and gases. These wastes include among others agricultural wastes and crop residues, excreta from animals, slaughterhouse waste, organic household waste, polluted waste water, wood processing residues, and waste from fruit markets. Each city produces tons of organic wastes daily from households, hospitals, industry offices, market centers, restaurants, etc. Every year in the world, several million tons of organic wastes are being disposed through different ways such as incineration, anaerobic digestion, land applications, and land filling.

This globally available and to be treated organic waste has a high potential to be used as a bio-renewable energy resource and to be turned into high-value by-products. This thematic issue titled "Energy provision from organic by-products, residues and wastes in Asia" within the Biomass Conversion and Biorefinery (Journal) highlights recent advances of our understanding on energy production from different waste streams in Asia.

The above thematic issue consists of state-of-the-art and original research works involving experimental and numerical studies, recent developments, and novel and emerging technologies in the area of energy production from organic waste. This thematic issue covers the thermo-chemical and biochemical conversion systems including gasification of palm kernel shells, groundnut shell, and Madhuca longifolia biomass to bioenergy. Additionally, saccharification of lignocellulosic biomass for bioethanol production, utilization of waste coconut meal for biodiesel and bioethanol production, and usage of beef tallow for biodiesel are tackled. Beside this, anaerobic digestion of perennial grass, textile industries wastes, food waste, and water hyacinth for biogas (biomethane) production have been addressed. We believe that the readers will enjoy reading the scientific articles and will collect many new scientific impressions and insights from this thematic issue.

Finally, we would like to thank the authors of this thematic issue for their valuable contributions and all the reviewers for their helpful comments and suggestions greatly helping to enhance the quality of the papers.

Publisher's Note Springer Nature remains neutral with regard to jurisdictional claims in published maps and institutional affiliations.
B. Deepanraj

babudeepan@gmail.com; deepanrajb@jecc.ac.in

1 Department of Mechanical Engineering, Jyothi Engineering College, Cheruthuruthy, Thrissur, India

2 Department of Mechanical Engineering, MEA Engineering College, Perinthalmanna, India

3 Department of Mechanical Engineering, National Institute of Technology Calicut, Kozhikode, India

4 School of Mechanical Engineering, Vellore Institute of Technology, Vellore, India 